\title{
Rose Lindsey, John Mohan, Elizabeth Metcalfe, Sarah Bulloch: Continuity and Change in Voluntary Action: Patterns, Trends and Understandings
}

\author{
Bristol, UK: Policy Press, 2019, 267 pp., £26.99
}

\author{
Dyana P. Mason ${ }^{1}$ (i)
}

Published online: 26 August 2019

(C) International Society for Third-Sector Research 2019

Has volunteering changed over time? Do policy shocks and policy priorities to incentivize volunteering change the shape and scope of voluntary action? This book seeks to answer these questions by tracing the available data on volunteering across several decades between 1979 and 2015 in the United Kingdom.

The book begins by considering the impacts different political eras have had on voluntary action and volunteering, from Margaret Thatcher's Conservative government starting in 1979 through Labour dominance from 1997 to 2010, and ends with the Coalition government of David Cameron from 2010 to 2015. Despite the differences in ideologies in national government over the decades, the authors find that perceptions, attitudes and participation in volunteering have remained remarkably stable over time.

The authors describe how every political era seemed to prioritize voluntary action and idealized civic engagement and self-reliance; however, each articulated a different "paradigm" of government approaches to voluntary action. Specifically, Margaret Thatcher's Conservative administration emphasized "personal responsibility" as a solution to social ills, which she described a "voluntary movement" (p. 20). This was followed by New Labour in 1997, which was greatly influenced by neoliberal values of innovation and third sector (non-profit) solutions to problems. Compare that to David Cameron's goal for the "Big Society" after taking office in 2010, which sought to encourage voluntary action in the shadow of austerity and reduced government expenditures on human services and welfare.

Dyana P. Mason

dmason@uoregon.edu

1 School of Planning, Public Policy and Management, University of Oregon, Eugene, OR 97403, USA
Both quantitative data and qualitative data presented in the book support the conclusion of stability. Quantitative data were marshalled through various regional and national surveys. Qualitative data were collected through the Mass Observation Index, a series of personal reflections on provided prompts by individuals. Overall, findings suggest that about two-thirds to three-quarters of the population are engaged in formal or informal volunteering of some typewhich has generally remained stable. This, despite a significant growth in the number of voluntary organizations, and increased employment and resources in the voluntary sector.

The authors are clear about the challenges in understanding the data; different survey instruments asked different questions in different years, and different surveys also defined volunteering quite differently. They overcome this challenge through the sheer amount of data they are able to review and analyse.

The authors end the book with a warning. As the desire to shrink government continues to grow, more volunteers may be needed. Yet, if volunteering continues to remain stable, there will be a growing number of needs that are not adequately met by private provision. This is a cautionary tale for those who study voluntary action, as well as for public policy practitioners who evaluate whether they can expect increased volunteering to solve our most pressing public problems. 